\title{
Cerebellar Encoding of Multiple Candidate Error Cues in the Service of Motor Learning
}

\author{
Christine C. Guo, ${ }^{1}$ Michael C. Ke, ${ }^{2}$ and ${ }^{\oplus}$ Jennifer L. Raymond ${ }^{2}$ \\ ${ }^{1}$ QIMR Berghofer Medical Research Institute, Herston, Queensland 4006, Australia, and ${ }^{2}$ Stanford University School of Medicine, Department of \\ Neurobiology, Stanford, California 94305-5125
}

For learning to occur through trial and error, the nervous system must effectively detect and encode performance errors. To examine this process, we designed a set of oculomotor learning tasks with more than one visual object providing potential error cues, as would occur in a natural visual scene. A task-relevant visual target and a task-irrelevant visual background both influenced vestibulo-ocular reflex learning in rhesus monkeys. Thus, motor learning does not identify a single error cue based on behavioral relevance, but can be simultaneously influenced by more than one cue. Moreover, the relative weighting of the different cues could vary. If the speed of the visual target's motion on the retina was low $(\ll 1 \%$ ), background motion dominated learning, but if target speed was high, the effects of the background were suppressed. The target and background motion had similar, nonlinear effects on the putative neural instructive signals carried by cerebellar climbing fibers, but with a stronger influence of the background on the climbing fibers than on learning. In contrast, putative neural instructive signals carried by the simple spikes of Purkinje cells were influenced solely by the motion of the visual target. Because they are influenced by different cues during training, joint control of learning by the climbing fibers and Purkinje cells may expand the learning capacity of the cerebellar circuit.

Key words: cerebellum; climbing fiber; error signal; eye movement; motor learning; Purkinje cell

\section{Introduction}

Much learning occurs through trial and error. Performance errors on one trial guide the modification of the neural circuitry controlling a behavior, leading to improved accuracy on subsequent trials (Lee and Schmidt, 2005; Medina and Lisberger, 2008; Shadmehr et al., 2010). This form of learning relies on the ability of the nervous system to identify and encode the relevant errors amid an ongoing stream of sensory and motor signals.

We studied the encoding of performance errors during oculomotor learning. The function of smooth eye movements is to stabilize images on the retina, hence image motion on the retina, or "retinal slip," can indicate a performance error, and the presence of retinal slip during eye movements can drive oculomotor learning. In the laboratory, oculomotor learning is usually studied using a single moving visual stimulus to create the retinal slip that drives learning. In a natural environment, however, there are typically multiple visual objects, whose motion on the retina can differ. For example, when a subject turns her head, images of objects at different distances move at different speeds and directions on the retina, depending on their position relative to the point of visual fixation. Moreover, primates can track a small visual target

\footnotetext{
Received Dec. 6, 2013; revised May 25, 2014; accepted May 31, 2014.

Author contributions: C.C.G., M.C.K., and J.L.R. designed research; C.C.G. and M.C.K. performed research; C.C.G. and M.C.K. analyzed data; C.C.G. and J.L.R. wrote the paper.

This work was supported by the U.S. National Institutes of Health (Grants R01 DC004154 and R01 NS072406 to J.L.R. and F31 DC008078 to M.C.K.), a Howard Hughes Medical Institute Fellowship for Medical Students and the Stanford Medical Scientist Training Program to M.C.K., and a Stanford Graduate Fellowship to C.C.G. We thank R. Levine and R. Hemmati for technical assistance.

The authors declare no competing financial interests.

Correspondence should be addressed to Jennifer Raymond at the above address. E-mail: jenr@stanford.edu. DOI:10.1523/JNEUROSCI.5114-13.2014

Copyright $\odot 2014$ the authors $\quad 0270-6474 / 14 / 339880-11 \$ 15.00 / 0$
}

(T), which can create motion of earth-stationary objects on the retina. Thus, to understand learning in the real world, one must understand the encoding of multiple potential error cues and their effects on learning. Therefore, we studied vestibulo-ocular reflex (VOR) learning in the presence of more than one visual cue.

The VOR stabilizes images on the retina during head movements by generating compensatory smooth eye movements in the direction opposite that of head motion. The VOR presumably evolved to stabilize large-field, rather than foveal, images, because it is a phylogenetically primitive oculomotor behavior that functions in species without a fovea. Accordingly, VOR learning can be induced by pairing passive head motion with coherent, large-field image motion (Ito et al., 1974; Miles and Fuller, 1974; Gonshor and Jones, 1976; Robinson, 1976; Watanabe, 1984). In primates, however, the oculomotor system has evolved the ability to track a small object of interest, using smooth pursuit eye movements. In the natural world, it would rarely be possible to stabilize images of both a small T and large-field background (BG) simultaneously. Therefore, we evaluated whether VOR learning in primates functions to improve the stabilization of a T or BG. We assessed the influence of T and BG motion on the changes in the VOR induced by training. We also analyzed the encoding of $\mathrm{T}$ and $\mathrm{BG}$ motion by cerebellar climbing fibers and Purkinje cells, which are thought to carry error signals that induce learning (Marr, 1969; Albus, 1971; Ito et al., 1977; Miles and Lisberger, 1981; Ito and Kano, 1982; Ke et al., 2009; Nguyen-Vu et al., 2013; Kimpo et al., 2014).

\section{Materials and Methods}

General procedures. Experiments were conducted on two male rhesus monkeys. The monkeys were trained to track a $\mathrm{T}$ to obtain liquid reinforcement. Surgery was performed to implant orthopedic plates for restraining the head, a coil of wire in one eye for measuring eye position 

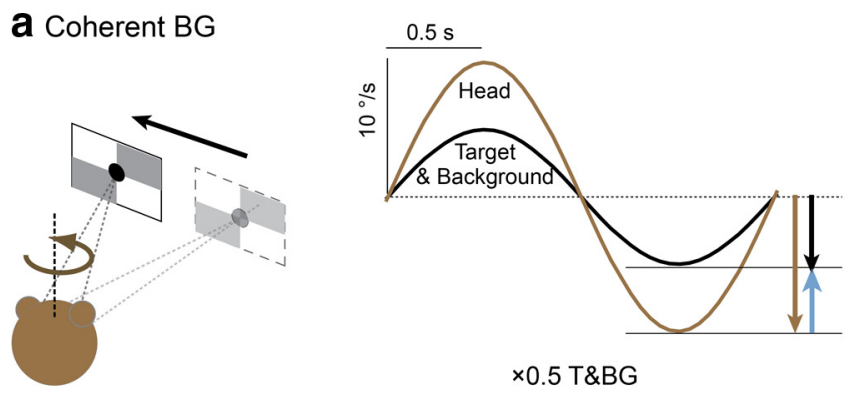

$\times 0.5$ T\&BG

\section{b Conflicting BG}
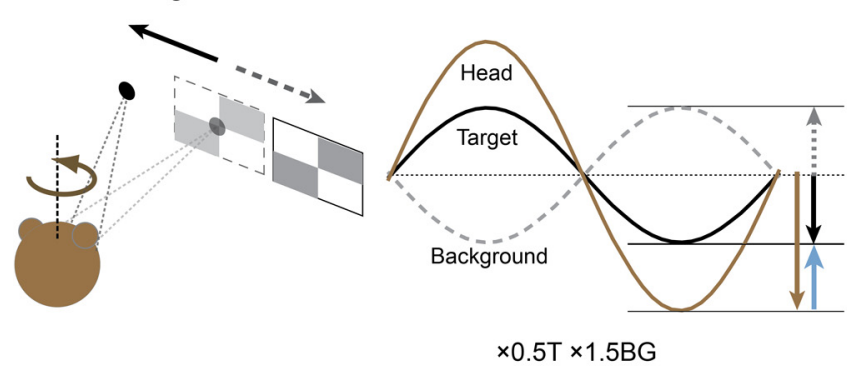
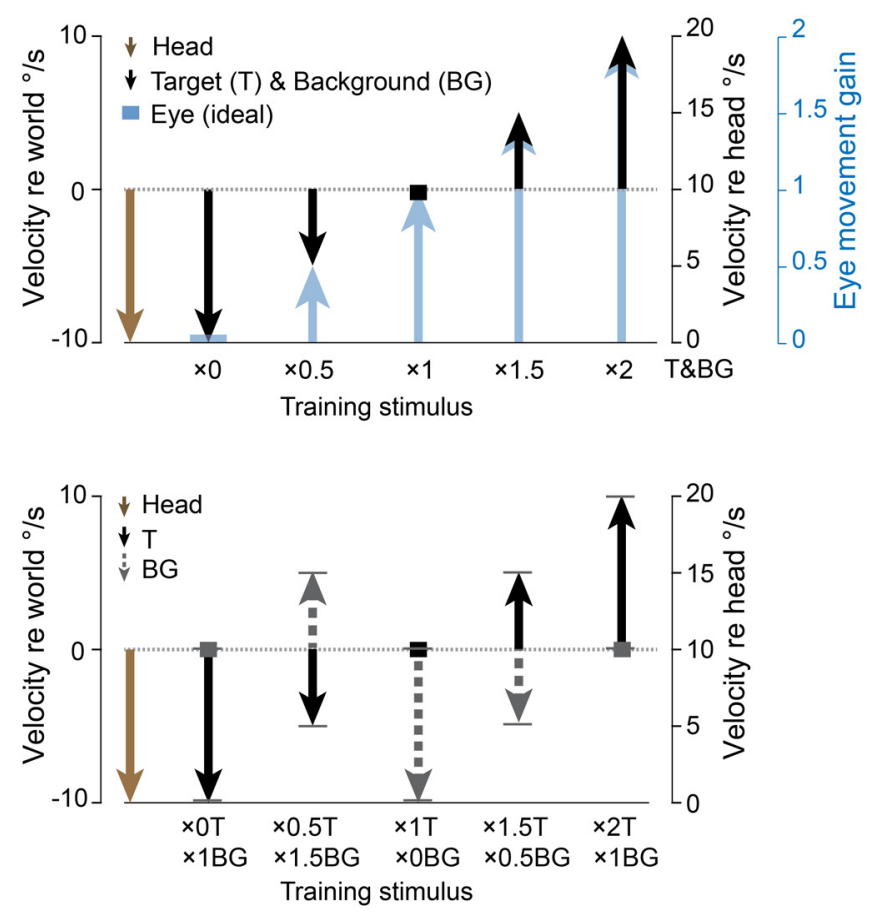

Figure 1. Training stimuli. $a$, Coherent training stimuli. Head rotation (brown) was paired with motion of $T$ and BG, and the $T$ and BG moved exactly together (black trace). T and BG varied across the five training stimuli (black), and could be in the same direction (downward vectors) or opposite direction (upward vectors) from head motion. The motion of the T and BG determined the ideal eye-movement response (blue vectors) required to stabilize the images on the retina. Peak velocity of head, T, BG, and the ideal eye movement are indicated by the head of the vector in world coordinates (right, vertical axis on left) and relative to head motion (right, black vertical axis on right). The gain of the ideal eye movement (which equals the ratio of eye speed, relative to the head, to the head speed, relative to the world) is also indicated (right, blue vertical axis). $\boldsymbol{b}$, Conflicting training stimuli. Head rotation was paired with motion of a T and BG that moved independently (see text for details). Black solid traces and vectors, motion of the T; gray dashed traces and vectors, motion of the BG. For all five conflicting stimuli, peak speed of the BG relative to the T was $10 \%$ /s (distance between heads of the gray and black vectors).

(Robinson, 1963; CNC Engineering), and a recording cylinder, which was aimed at the cerebellar flocculus and ventral paraflocculus, using stereotaxic coordinates. During experiments, the head of the monkey was restrained by securing the implanted head holder to a primate chair. Vestibular stimuli were delivered using a servo-controlled turntable (Ideal Aerosmith) to rotate the animal about an earth-vertical axis. To induce learning, a vestibular stimulus was paired with motion of two visual stimuli: a small $\mathrm{T}$, which the animal was rewarded for tracking, and a large visual BG. The T subtended $0.5^{\circ}$ of visual angle. The BG was a $20 \times$ $30^{\circ}$ grid of $1.5 \times 1.5^{\circ}$ black and white squares. The T and BG visual stimuli were projected onto the back of a tangent screen $114 \mathrm{~cm}$ in front of the eyes, and could be moved independently using mirror galvanometers. All surgical and behavioral procedures conformed to guidelines established by the U.S. Department of Health and Human Services (National Institutes of Health) Guide for the Care and Use of Laboratory Animals, as approved by Stanford University. A subset of these data was published previously (Ke et al., 2009).

Behavioral experiments. VOR learning was induced by presenting combined visual-vestibular stimuli for $2 \mathrm{~h}$ (Monkey L) or $1 \mathrm{~h}$ (Monkey E). The longer training period was used in Monkey L because he consistently tracked the $\mathrm{T}$ during the full $2 \mathrm{~h}$ of training, whereas Monkey E's tracking of the $\mathrm{T}$ fell off during the second hour of training. VOR performance was tested before and after training by delivering the vestibular stimulus (i.e., rotating the monkey) in total darkness to eliminate any visual influence on eye movements. The vestibular stimulus used to measure the VOR and induce learning was always $0.5 \mathrm{~Hz}$ sinusoidal head rotation about an earth-vertical axis, with peak speed of $10 \%$.

To induce learning, the vestibular stimulus was paired with different combinations of $\mathrm{T}$ and $\mathrm{BG}$ motion. The visual-vestibular training stimuli are described by a notation indicating the eye-movement gain (relative to head movement) required to stabilize the image of the $\mathrm{T}$ and $\mathrm{BG}$ on the retina. When the T moved exactly with the head, the eye velocity (relative to the head) and eye-movement gain required to stabilize the image of the $\mathrm{T}$ on the retina were zero, hence the training stimulus is described as " $\times 0 \mathrm{~T}$ " (Fig. $1 a$, $\times 0$ ). When the $\mathrm{T}$ moved at the same speed as the head but $180^{\circ}$ out of phase with the head, so that the eye movement required to stabilize the $\mathrm{T}$ on the retina had a peak speed of $20 \%$, or $2 \times$ the speed of the head, the stimulus is described as " $\times 2$ T" (Fig. $1 a, \times 2$ ). During the $\times 0.5$ T training stimulus, the $\mathrm{T}$ moved in the same direction as the head, but at half the speed, so that the eye-movement speed required to stabilize the $\mathrm{T}$ was $5 \%$, or $0.5 \times$ the speed of the head (Fig. $1 a, \times 0.5$ ). During the $\times 1.5 \mathrm{~T}$ training stimulus, the T moved in the opposite direction as the head, and at half the speed, so that the eyemovement speed required to stabilize the $\mathrm{T}$ was $15 \%$, or $1.5 \times$ the speed of the head (Fig. $1 a, \times 1.5$ ). During training stimuli with $\times 1 \mathrm{~T}$, the T was earthstationary (Fig. 1a). Similar terminology was used to describe the motion of the BG stimulus during training (Fig. $1 b$, gray).

We used five pairs of visual-vestibular training stimuli (Table 1, top two rows). This set included five coherent training stimuli, in which the visual BG moved exactly with the $\mathrm{T}: \times 0 \mathrm{~T} / \times 0 \mathrm{BG}, \times 0.5 \mathrm{~T} / \times 0.5 \mathrm{BG}, \times 1 \mathrm{~T} /$ $\times 1 \mathrm{BG}, \times 1.5 \mathrm{~T} / \times 1.5 \mathrm{BG}$, and $\times 2 \mathrm{~T} / \times 2 \mathrm{BG}$. The five corresponding conflicting training stimuli were $\times 0 \mathrm{~T} / \times 1 \mathrm{BG}, \times 0.5 \mathrm{~T} / \times 1.5 \mathrm{BG}, \times 1 \mathrm{~T} / \times 0 \mathrm{BG}$, $\times 1.5 \mathrm{~T} / \times 0.5 \mathrm{BG}$, and $\times 2 \mathrm{~T} / \times 0 \mathrm{BG}$ stimuli, where the visual $\mathrm{BG}$ moved independently from the $\mathrm{T}$, with peak speed relative to the $\mathrm{T}$ of $10 \%$ s. In Figure 1, the motion of the head, T, and BG, and the fully compensatory eye-movement responses for the coherent and conflicting training stimuli are represented in both world-centered and head-centered coordinates. For example, during the $\times 1.5$ stimulus, the peak speed of the $T$ and $\mathrm{BG}$ were $5 \%$ s relative to the world (distance to head of black vector from zero on the vertical axis on left), but $15 \%$ s relative to the head (distance to head of black vector from head of brown vector, which is what defines zero on the vertical axis on the right).

In addition, we recorded climbing fibers when the T moved with the head, $\times 0 \mathrm{~T}$, and the $\mathrm{BG}$ moved at one of several different speeds $(\times 0 \mathrm{~T} / \times 0.5 \mathrm{BG}$, $\times 0 \mathrm{~T} / \times 1 \mathrm{BG}, \times 0 \mathrm{~T} / \times 1.5 \mathrm{BG}, \times 0 \mathrm{~T} / \times 2 \mathrm{BG})$ or when the $\mathrm{T}$ moved in the $\mathrm{di}-$ rection opposite to the head, $\times 2 \mathrm{~T}$, and the $\mathrm{BG}$ moved at one of several different speeds $(\times 2 \mathrm{~T} / \times 0.5 \mathrm{BG}, \times 2 \mathrm{~T} / \times 1 \mathrm{BG}, \times 2 \mathrm{~T} / \times 1.5 \mathrm{BG}, \times 2 \mathrm{~T} / \times 2 \mathrm{BG})$ 
Table 1. Summary of visual-vestibular training stimuli

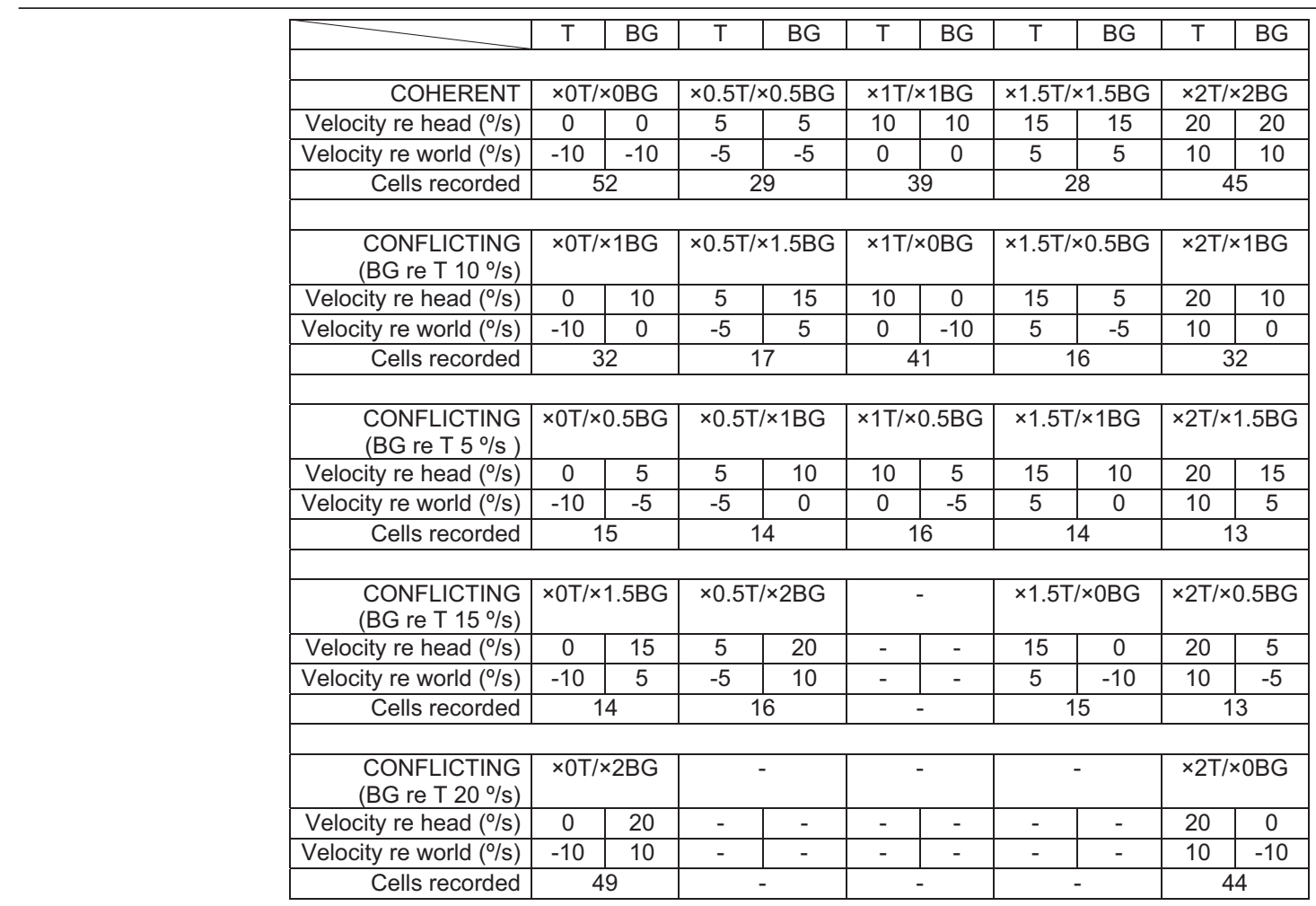

(Table 1, bottom). We tested the ability of a subset of these additional stimuli $(\times 0 \mathrm{~T} / \times 0.5 \mathrm{BG}, \times 0 \mathrm{~T} / \times 2 \mathrm{BG}, \times 2 \mathrm{~T} / \times 0.5 \mathrm{BG}$, and $\times 2 \mathrm{~T} / \times 1.5 \mathrm{BG})$ to induce VOR learning.

Experiments to induce learning were separated by $\geq 24 \mathrm{~h}$ to allow the gain of the VOR to recover to its normal value before the next experiment. No specific training was delivered to drive the VOR gain back to normal, aside from exposure to the normal visual-vestibular environment of the home cage. In each monkey, there were $\geq 3$ replications of the behavioral experiments for each training stimulus.

Electrophysiology. Tungsten electrodes (FHC, Microprobe) were used to make extracellular recordings from Purkinje cells in the floccular complex of the cerebellum, comprising the cerebellar flocculus and ventral paraflocculus. The floccular complex was identified based on stereotaxic coordinates and electrophysiological landmarks, such as the number of cerebellar layers penetrated by the electrode, the presence of eyemovement-related responses, and location relative to other structures, such as the dorsal cochlear nuclei and vestibular nerves, which have their own characteristic electrophysiological signatures. Purkinje cells were identified by their simple spike waveforms, mean firing rate, coefficient of variation of interspike interval, location within the layers of the cerebellar cortex (as determined by the BG electrophysiological activity), and, in most cases, by the presence of a complex spike. Once a Purkinje cell was isolated, its sensitivity to eye velocity and head velocity were measured by recording its simple spike responses during (1) smooth pursuit eye movements evoked by horizontal motion of the $\mathrm{T}$ with a sinusoidal velocity profile at a frequency of $0.5 \mathrm{~Hz}$ and a peak velocity of $\geq 10 \%$ and (2) as the monkey cancelled his VOR by tracking a $\mathrm{T}$ that moved exactly with sinusoidal head rotation about an earth-vertical axis at $0.5 \mathrm{~Hz}$ and at a peak velocity of $\geq 20 \%$ s. Our analysis focused on horizontal gaze-velocity Purkinje cells (HGVPs), which have been implicated in VOR learning (Lisberger and Fuchs, 1978; Miles et al., 1980; Lisberger et al., 1994). Purkinje cells were classified as HGVPs if they met the following criteria: (1) during horizontal smooth pursuit eye movements, simple spike firing rate was modulated by $\geq 0.3$ spikes/s per degree/s, and there was a phase difference of $<45^{\circ}$ between peak firing rate and peak ipsiversive eye velocity; and (2) during cancellation of the VOR, simple spike firing rate was modulated by $\geq 0.3$ spikes/s per degree/s and the phase difference between peak firing rate and peak ipsiversive head velocity was $<45^{\circ}$ (Lisberger and Fuchs, 1978; Raymond and Lisberger, 1998).

The complex spikes recorded in a Purkinje cell provide a measure of activity in its climbing fiber input, since spikes in a climbing fiber trigger complex spikes in its Purkinje cell targets in a one-to-one manner (Eccles et al., 1967). Therefore we refer to the complex spike activity of a Purkinje cell as a climbing fiber response. Complex spikes were well isolated in 52 of 62 HGVPs recorded. In the other 10 HGVPs, complex spikes were sometimes detected, but were not well enough isolated to include in the analysis.

To compare neural responses across training stimuli, we recorded from the same Purkinje cell during the presentation of as many different visual-vestibular training stimuli as possible within a single recording session. The median number of training stimuli tested on each cell was 12. Each training stimulus was presented for 60-90 s. Training stimuli with the same T motion, combined with different BG motion, were delivered in one block; and the order of blocks was pseudorandomized. Data files were only included in the analysis if eye position was within $2^{\circ}$ of $\mathrm{T}$ position for $90 \%$ of the entire $60-90 \mathrm{~s}$ presentation of a training stimulus. In separate behavioral experiments, we tested the ability of each training stimulus, presented continuously for $1-2 \mathrm{~h}$, to induce VOR learning.

Statistical analysis. Data analysis was performed in Matlab and Excel. The position and velocity of the eye, head, and visual stimulus were sampled at $500 \mathrm{~Hz} /$ channel. Eye-velocity records were edited to remove the rapid deflections caused by saccades. The smooth eye velocity data were then analyzed by aligning stimulus cycles on head velocity, and averaging. Most averages contained $\geq 10$ cycles. Analysis of the VOR in the dark was limited to cycles for which gaze position was within $15^{\circ}$ of straight-ahead gaze. A sinusoidal function with a frequency of $0.5 \mathrm{~Hz}$ was fit to the average eye and head velocity traces in Matlab, following previous procedures (Ke et al., 2009; Guo and Raymond, 2010). The peak eye velocity and peak head velocity derived from the fitted sinusoidal functions were used to calculate the gain of the VOR, as the ratio of peak eye velocity to peak head velocity. To calculate the retinal slip of the T and the BG, we computed the difference between the eye velocity and the T or BG visual stimulus velocity, respectively, at each time point. Sinusoidal func- 
tions were fit to these difference traces, and the amplitude of the sinusoidal function was used as the estimate of peak retinal slip.

Purkinje cell simple spikes were detected using a hardware window discriminator (Bak Electronics). Complex spikes were discriminated using off-line spike sorting with time and amplitude windows or templatematching algorithms (Spike2, Cambridge Electronic Design). We confirmed each sorted complex spike by examining the raw traces. The simple spike data were analyzed by aligning the records on head velocity. The amplitude and phase of the simple spike responses were determined from the fundamental components provided by Fourier analysis of the averages.

Because firing rate of the climbing fibers was close to zero in some cells during visual stimulus motion in the "off" (ipsiversive) direction, the climbing fiber responses were often not well fit by a sinusoid. Therefore, a vector analysis was used to quantify the response of each individual climbing fiber to each training stimulus, following previous methods (Ke et al., 2009). The stimulus cycle was divided into 1000 equal bins, with each bin corresponding to a particular phase relative to head velocity. A vector was assigned to each bin, with a length equal to the average firing rate of the climbing fiber in that bin (see Fig. $3 a$, for illustration purposes, 16 rather than 1000 bins are shown). The vector sum was then used to summarize the climbing fiber response of each cell to each stimulus. The phase of the vector sum (corresponding to the direction of the vectors in Figs. $3 a, 4 a$ ) was used as our measure of the phase of the climbing fiber response. The amplitude of the climbing fiber response was measured as one half the amplitude of the vector sum (to correspond approximately to the amplitude that would be extracted using a Fourier analysis, which reflects half the trough-to-peak amplitude).

The data from each monkey were normalized to generate a combined dataset from the two monkeys. For each monkey, a sigmoidal curve was fit to the mean $\triangle$ VOR gain or mean climbing fiber responses measured for each of the different coherent training stimuli (Fig. $3 b, d$ ). The asymptotic values from the sigmoidal fits were used to normalize the individual data points from each monkey for each training stimulus, so that data from the two monkeys could be combined. Thus, the largest changes in VOR gain or climbing fiber responses in each monkey would have values close to 1 .

A threshold of $p<0.05$ was used to determine significance (ANOVA, post hoc Tukey's test, Pearson correlation analysis).

\section{Results}

We induced VOR learning in two rhesus monkeys by pairing a vestibular stimulus with two visual stimuli-a small visual $\mathrm{T}$, which the animal tracked with his eyes for a reward, and a large visual $B G$ that could move independently. In some cases, the T and BG moved together during training to provide consistent, unambiguous error cues (Fig. 1a). Five such coherent training stimuli were tested, denoted $\times 0, \times 0.5, \times 1, \times 1.5$, and $\times 2$, where the notation $\times a$ refers to a training stimulus that required a tracking eye-movement gain of $a$ relative to the head movement to stabilize the visual stimuli on the retina (Fig. $1 a$; Table 1; see Materials and Methods for details). We further tested a set of five conflicting training stimuli, in which the $\mathrm{T}$ and $\mathrm{BG}$ did not move coherently during training, so that different eye movements would be required to stabilize the $\mathrm{T}$ versus the $\mathrm{BG}$ on the retina (Fig. $1 b$ ). The five conflicting training stimuli were as follows: $\times 0 \mathrm{~T} / \times 1 \mathrm{BG}, \times 0.5 \mathrm{~T} / \times 1.5 \mathrm{BG}, \times 1 \mathrm{~T} / \times 0 \mathrm{BG}, \times 1.5 \mathrm{~T} / \times 0.5 \mathrm{BG}$, and $\times 2 \mathrm{~T} / \times 1 \mathrm{BG}$, where the notation $\times a \mathrm{~T} / \times b \mathrm{BG}$ indicates that $\mathrm{a}$ tracking eye-movement gain of $a$ was required to stabilize the $\mathrm{T}$ on the retina, whereas a tracking eye-movement gain of $b$ was required to stabilize the BG on the retina (Table 1). These conflicting stimuli were designed so that (1) the motion of the $\mathrm{T}$ on the retina should induce an increase in VOR gain, while the motion of the BG should induce a decrease in VOR gain, or vice versa, and (2) the difference between peak T and BG motion was always $10 \%$ (Fig. 1 , distance between black and gray vector tips).

Monkeys were rewarded for and skilled at tracking the T. Therefore the actual eye velocity during training was close to that required to stabilize the $\mathrm{T}$ (compare actual eye movements in Fig. $2 b$, with ideal eye movements in Fig. $1 a$, blue bars). Moreover, eye velocity was not significantly influenced by the motion of the BG (Fig. $2 b$; coherent vs conflicting, $p>0.2$, ANOVA). Therefore, the speed of T motion on the retina, or "T slip," was not influenced by the BG (Fig. $2 c ; p>0.2$, ANOVA). Thus, by delivering the same T motion but different BG motion, we created pairs of coherent and conflicting training stimuli with similar vestibular input, eye movements (Fig. $2 b$ ), and T slip (Fig. 2c), but different BG slip on the retina (Fig. $2 d$; coherent vs conflicting, $p<0.0001$, ANOVA). This design enabled us to assess the effect of BG motion on learning.

\section{Training with coherent $\mathrm{T}$ and $\mathrm{BG}$ motion}

When the $\mathrm{T}$ and $\mathrm{BG}$ moved together during training, the direction of VOR learning was determined by the direction of motion of the visual stimuli relative to the head, as shown previously (Ito et al., 1974; Miles and Fuller, 1974; Gonshor and Jones, 1976; Robinson, 1976; Watanabe, 1984). The normal, baseline VOR gain, measured in darkness, was $0.87 \pm 0.03$ in Monkey $\mathrm{L}$ and $0.89 \pm 0.04$ in Monkey E. When a smaller eye-movement gain was required to track the visual stimuli, retinal slip was in the same direction as head motion (Fig. $3 a, \times 0, \times 0.5$, red traces; if the eye moves too much in the opposite direction from the head, image motion will be in the same direction as the head; Fig. 2a), and training reduced the VOR gain (Fig. $3 a$, blue traces; Fig. 3b; $\times 0, \times 0.5$ training stimuli). When a larger eye-movement gain was required to track the visual stimuli, retinal slip was in the opposite direction from head motion (Fig. $3 a, \times 1, \times 1.5, \times 2$, red traces), and training increased the VOR gain (Fig. $3 a$, blue traces; Fig. $3 b ; \times 1, \times 1.5, \times 2$ training stimuli). The amount of learning varied with the speed of retinal slip during training (Fig. $3 c$ ).

The responses of climbing fibers during coherent training reflected the direction of the retinal slip, which is consistent with previous studies showing that the climbing fibers encode the error signals provided by retinal slip when oculomotor learning is induced using coherent, full-field image motion, or motion of a single visual stimulus against a dark BG (Simpson and Alley, 1974; Ghelarducci et al., 1975; Lisberger and Fuchs, 1978; Watanabe, 1984; Nagao, 1988; Stone and Lisberger, 1990). Climbing fiber activity increased during contraversive retinal slip (Waespe and Henn, 1981; Blanks and Precht, 1983; Graf et al., 1988; Kusunoki et al., 1990; Stone and Lisberger, 1990; Fushiki et al., 1994; Fig. 3a, spike frequency histograms), which coincided with contraversive head movement during the $\times 0$ and $\times 0.5$ training stimuli (Fig. $3 a, d$, negative values) and with ipsiversive head movement during the $\times 1, \times 1.5$, and $\times 2$ training stimuli (Fig. $3 a$, $d$, positive values). The phases of the climbing fiber responses had a bimodal distribution, with phase values clustered near peak ipsiversive and peak contraversive head velocity (Fig. $3 d$, top). Therefore, a single scalar value was used to summarize the climbing fiber responses, with the absolute value indicating the amplitude of the firing rate modulation, and the sign indicating the phase (positive values to indicate peak firing near peak ipsiversive head velocity, and negative values to indicate peak firing near peak contraversive head velocity; Fig. $3 d$ ). The amplitude of the climbing fiber responses varied with the speed of retinal slip during the five coherent training stimuli tested (Fig. 3e), as also observed for learning (Fig. 3c).

The results from two monkeys were qualitatively similar, but differed quantitatively (Fig. $3 b, d$, diamonds and circles). On average, the climbing fiber responses were bigger in Monkey $\mathrm{E}$ than in Monkey L (Fig. 3d). However, the amount of learning was bigger in Monkey L than in Monkey E (Fig. 3b), at least in part because Monkey L reliably tracked the T for longer periods, mak- 
a

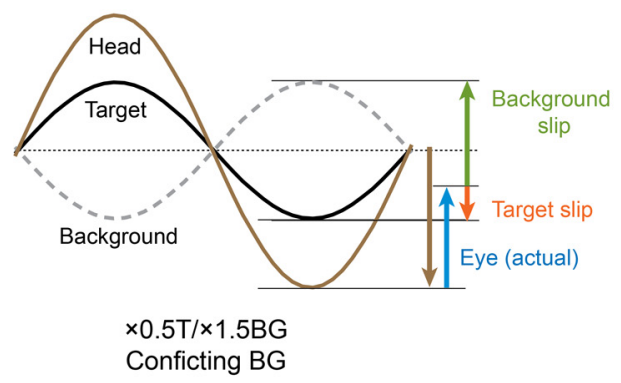

C

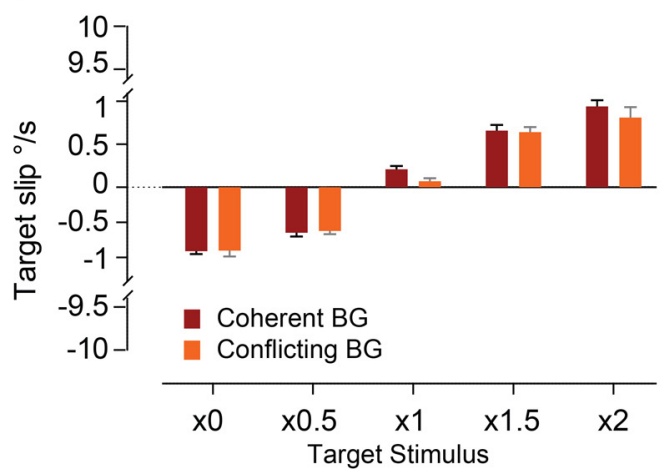

b

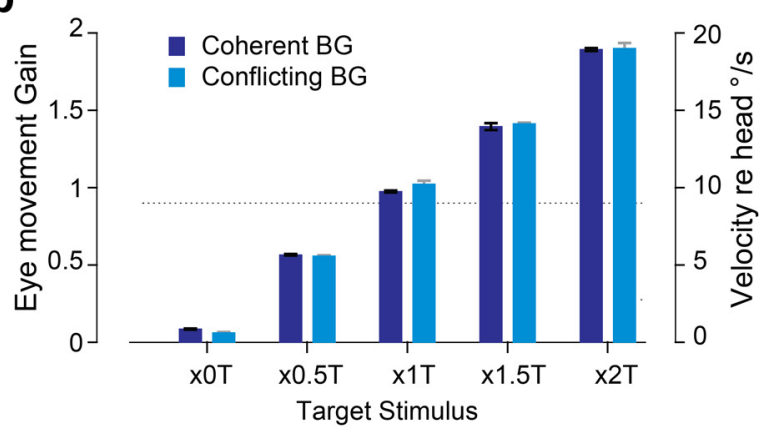

d

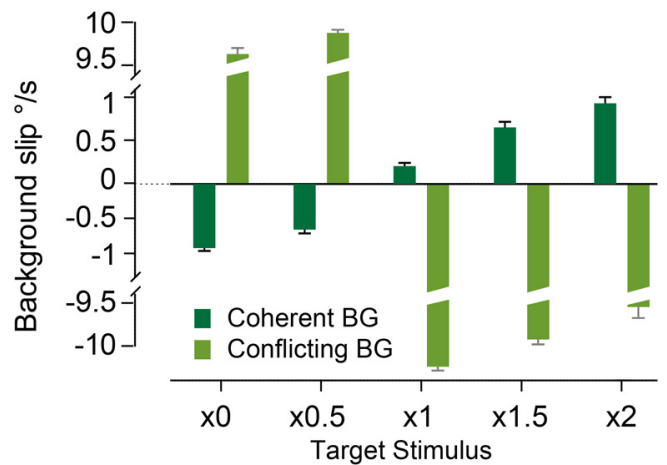

Figure 2. Eye movements and retinal slip during training. $a$, Traces of head (brown), $T$ (black), and BG (gray) motion during an example conflicting training stimulus ( $\times 0.5 \mathrm{~T} / \times 1.5 B G$ ). Blue vector represents the peak velocity of the eye movement. Retinal slip is measured as the difference between movement of the visual stimuli and the eye. Red and green vectors represent the peak velocity of the retinal slip of $\mathrm{T}$ and $\mathrm{BG}$, respectively. $\boldsymbol{b}$, Eye movements (vertical axis on left, gain relative to head; vertical axis on right, peak velocity relative to head) measured during the coherent training stimuli (dark blue) were similar to those measured during the corresponding conflicting training stimuli (light blue) with the same T stimulus. During all training stimuli, the eye-movement gain was close to that required to stabilize the T on the retina (compare with Fig. 1a, blue arrows). Dotted line indicates the baseline gain of the VOR. $c$, T motion on the retina (slip) during coherent (dark red) and conflicting (light red) training stimuli. $\boldsymbol{d}, \mathrm{BG}$ motion on the retina (slip) during coherent (dark green) and conflicting (light green) training stimuli. Broken scale bars are used to show both the subtle differences in the BG slip (or T slip) across different T stimuli as well as the large difference in BG slip for the conflicting versus coherent training stimuli.

ing it possible to use longer training periods for the behavioral experiments (see Materials and Methods). Therefore, to compare the relative efficacy of the different coherent and conflicting training stimuli, we normalized both the behavioral and neural results for each monkey (see Materials and Methods for details) before combining the data from the two monkeys.

\section{Conflicting T and BG motion: effects on learning}

To determine how the small $\mathrm{T}$ and large visual BG each affect VOR learning, we compared the learned changes in the VOR induced by coherent and conflicting training stimuli (Fig. $4 a-e$ ). The same $\mathrm{T}$ stimuli induced different VOR learning when presented with conflicting (Fig. $4 b$, gray bars) versus consistent BG motion (Fig. $4 b$, black bars; $p<0.01$, ANOVA; $p<0.001$, post hoc Tukey's test). In some cases $(\times 0$ or $\times 2 \mathrm{~T})$, the conflicting BG motion had a moderate effect on learning - it reduced the amount but did not change the direction of learning (Fig. $4 b$, gray vs black bars). However, in other cases, conflicting BG motion had a more dramatic effect-it eliminated learning $(\times 1.5 \mathrm{~T})$ or reversed the direction of learning $(\times 0.5$ or $\times 1 \mathrm{~T}$; Fig. $4 b$, gray vs black bars). We evaluated which factor(s) determine the effect of conflicting BG motion on learning.

The effect of the BG on learning was quantified as the absolute difference between the learned changes induced when there was coherent versus conflicting BG motion for each T stimulus (Fig. 4c). The BG effect varied significantly across the five pairs of coherent and conflicting training stimuli (Fig. $4 c ; p<0.001$, ANOVA). These variations in BG effect were linearly correlated with the speed of $\mathrm{T}$ slip on the retina during training (Fig. $5 a ; R^{2}=0.98, p<0.001$ ) - when T slip speed was the lowest $(\times 1 \mathrm{~T})$, the motion of the BG had the greatest effect on learning (Fig. $5 a$, circle), with progressively less effect of the BG for higher T slip speeds.

Learning was relatively insensitive to the speed of the BG slip. The conflicting stimuli were designed to create similar BG motion on the retina $\left(\sim 10^{\circ} / \mathrm{s}\right)$, yet there were small variations across the five conflicting training stimuli (from 9.1 to $9.9 \%$ s; Fig. $2 d$, light green). To evaluate whether these small variations in the BG slip speed could account for its varying effects on learning (Fig. $4 c$ ), we designed additional stimuli to create varying conflicting BG motion (from 5 to $20^{\circ} / \mathrm{s}$ ) with a given T, using either $\times 0$ or $\times 2$ T's (Fig. $5 b$, open symbols; see Materials and Methods for details). We found that the effect of the BG on learning was similar across the range of conflicting BG slip speeds tested (Fig. 5b; $\left.R^{2}<0.05, p>0.5\right)$. Thus, learning was fairly insensitive to the speed of the BG slip in the range from 5 to $20 \%$, and therefore the substantial variations we observed in the amplitude of the BG's effect on learning across different training stimuli (Fig. $4 c$ ) could not be attributed to small variations in BG slip speed.

Together, the results indicate that the effect of a given BG stimulus does not simply sum with the effect of whatever T stimulus is present. Rather, the effect of the BG is diminished when $\mathrm{T}$ slip speed is high.

\section{Conflicting T and BG motion: effects on climbing fiber responses}

The effects of the conflicting BG motion on the responses of climbing fibers paralleled the effects of the BG on learning. The effect of the $\mathrm{BG}$ on the climbing fibers was quantified as the absolute difference 
a
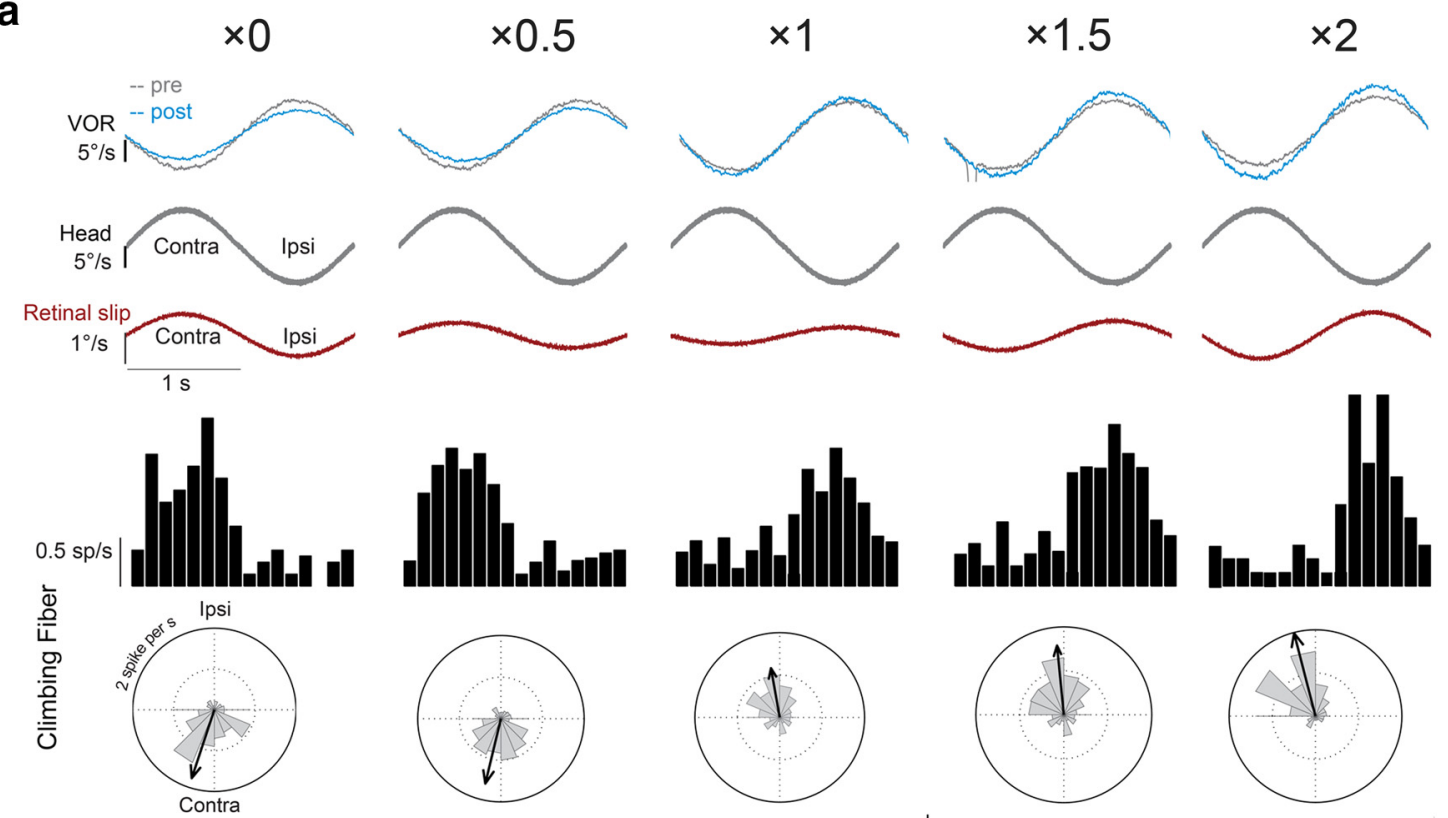

b
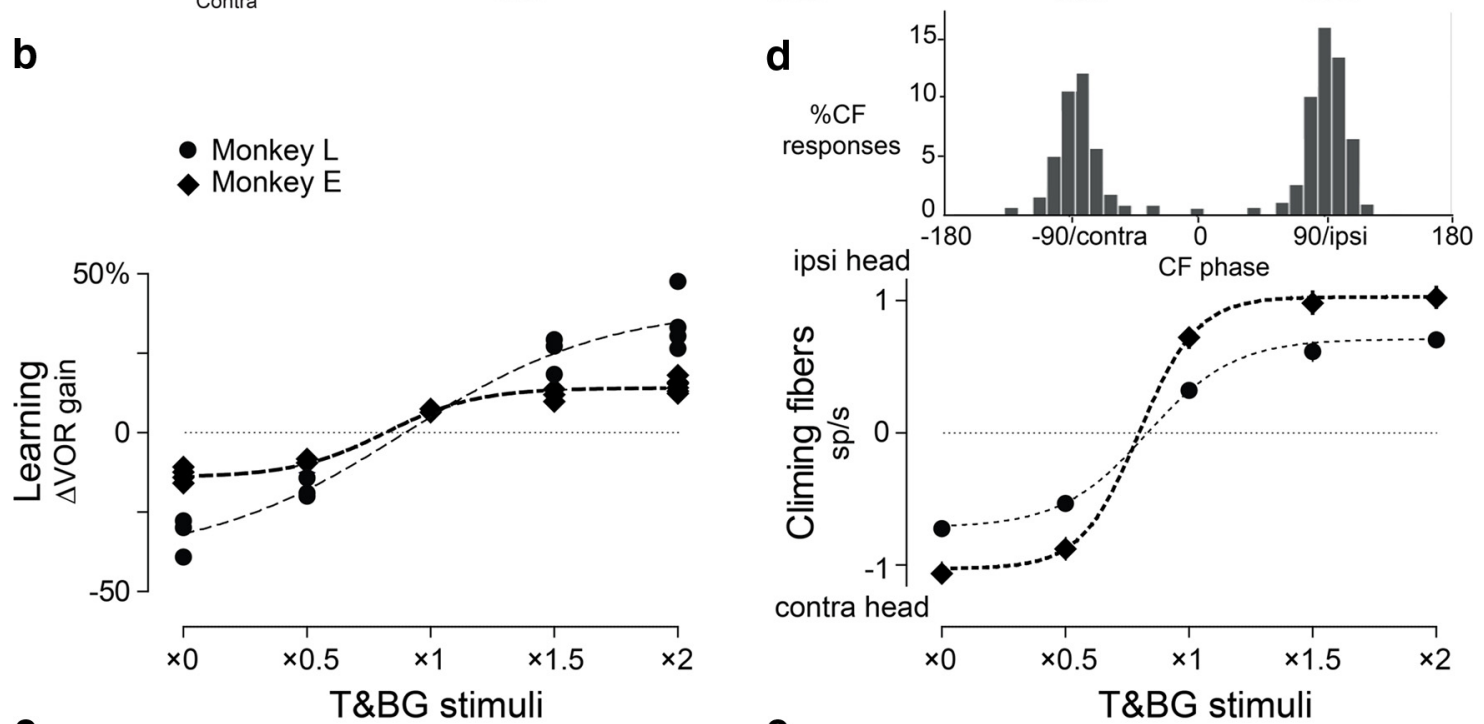

C

- Monkey L
- Monkey E
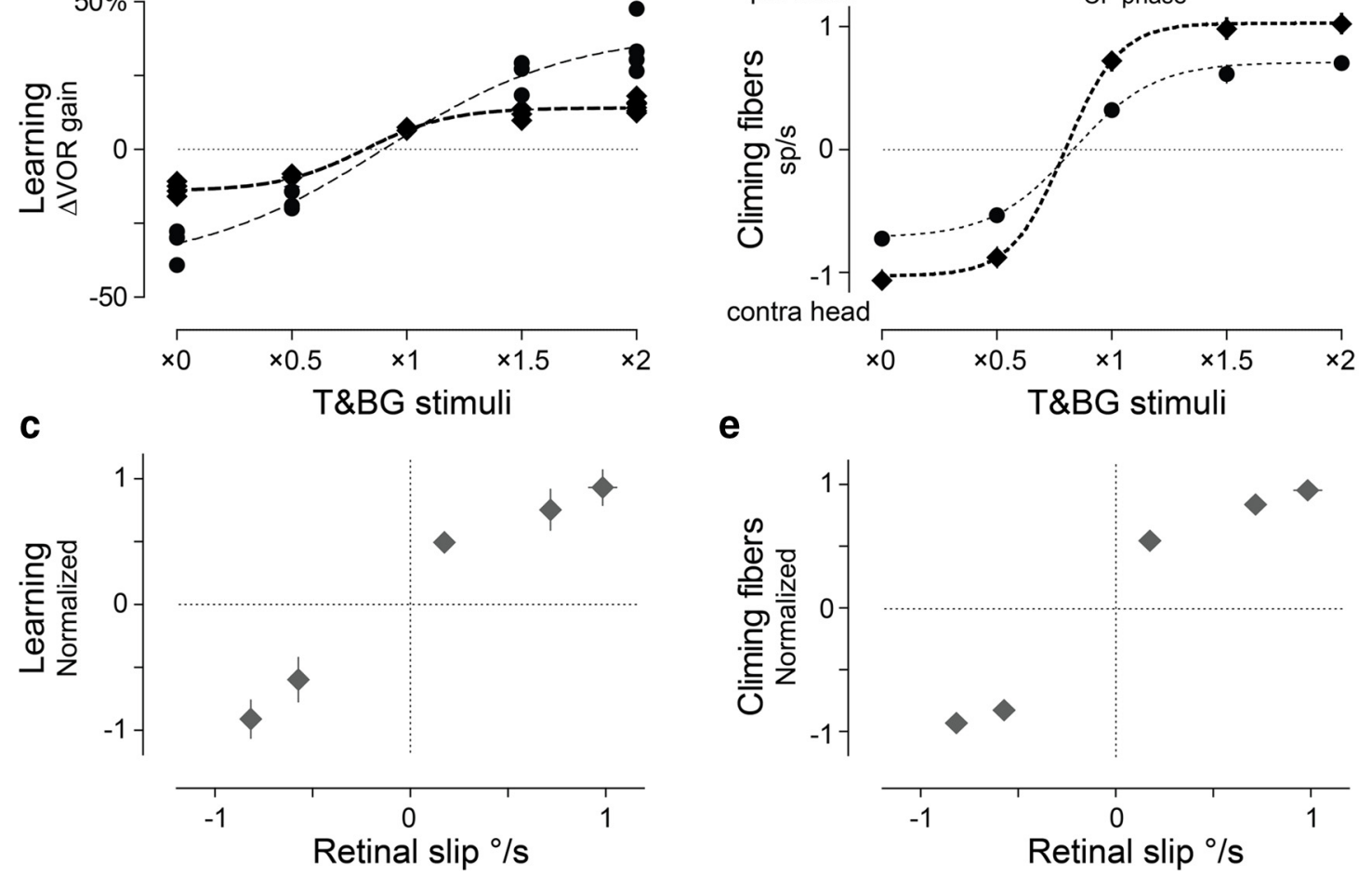

e

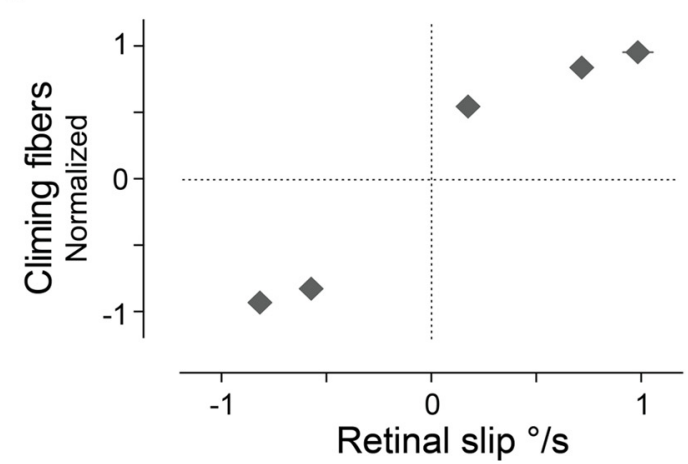

Figure 3. Learning and climbing fiber responses during the coherent training stimuli. $\boldsymbol{a}$, Representative learning and climbing fiber responses. From top to bottom rows, Eye velocity traces showing VOR responses tested in the dark pretraining (gray) and post-training (blue); average head motion during training and VOR testing; retinal slip during training stimuli; spike frequency histograms and polar plots of the responses of a representative climbing fiber to the training stimuli. In the polar plots, the gray pie wedges represent firing rate at each phase of head motion, vectors quantify the amplitude and phase of firing rate modulation (see Materials and Methods). Clockwise, Phase lead. $\boldsymbol{b}$, Learning was measured as the percentage change in VOR gain after training compared with pretraining. Each point represents the result from a single training session in Monkey L (circles) or Monkey E (diamonds). Dotted lines represent sigmoidal fits for each monkey. $c$, Normalized and averaged learning in two monkeys plotted against peak retinal slip of $\mathrm{T}$ and BG. $\boldsymbol{d}$, Climbing fiber responses during training. Top, Histogram showing the distribution of phase of peak firing (relative to head velocity) for each climbing fiber to each training stimulus. Note clustering of values near 0 and $180^{\circ}$. Bottom, Average climbing fiber responses. Positive values indicate peak firing during ipsiversive head motion. Negative values indicate peak firing during contraversive head motion. Each point represents the mean response in the population of climbing fibers recorded in one monkey (in spikes/s). Dotted lines represent sigmoidal fits for each monkey. $\boldsymbol{e}$, Normalized and averaged climbing fiber responses from two monkeys plotted against peak retinal slip of T and BG. In c-e, error bars signify SEM and are sometimes smaller than the symbol size. 


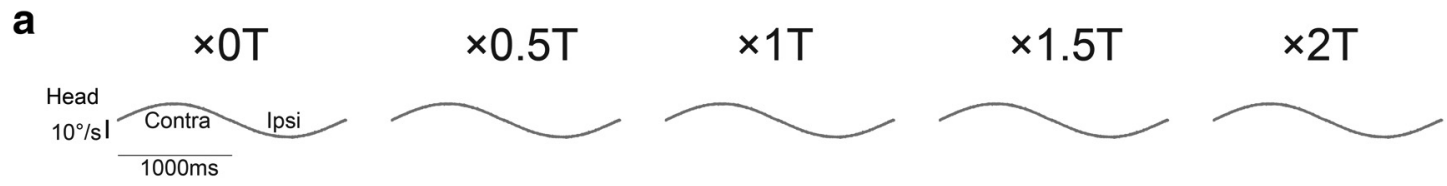

\section{Coherent background}

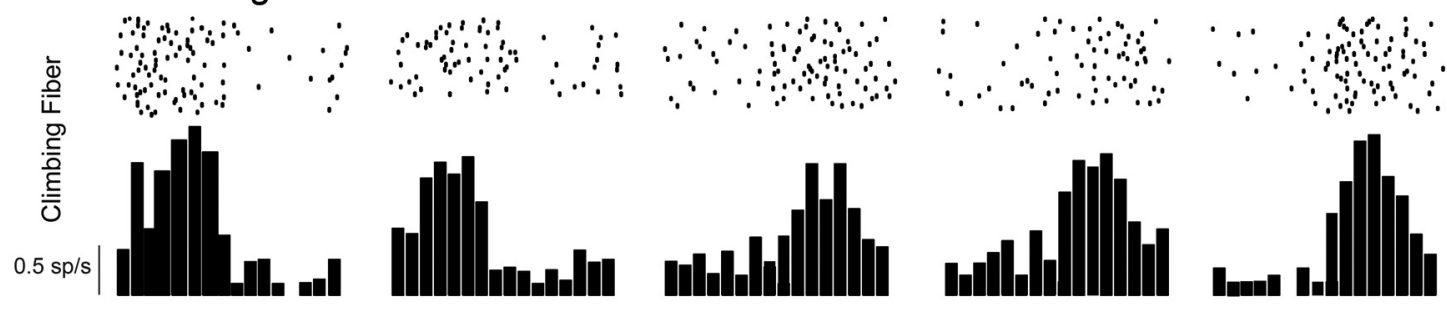

\section{Conflicting background}

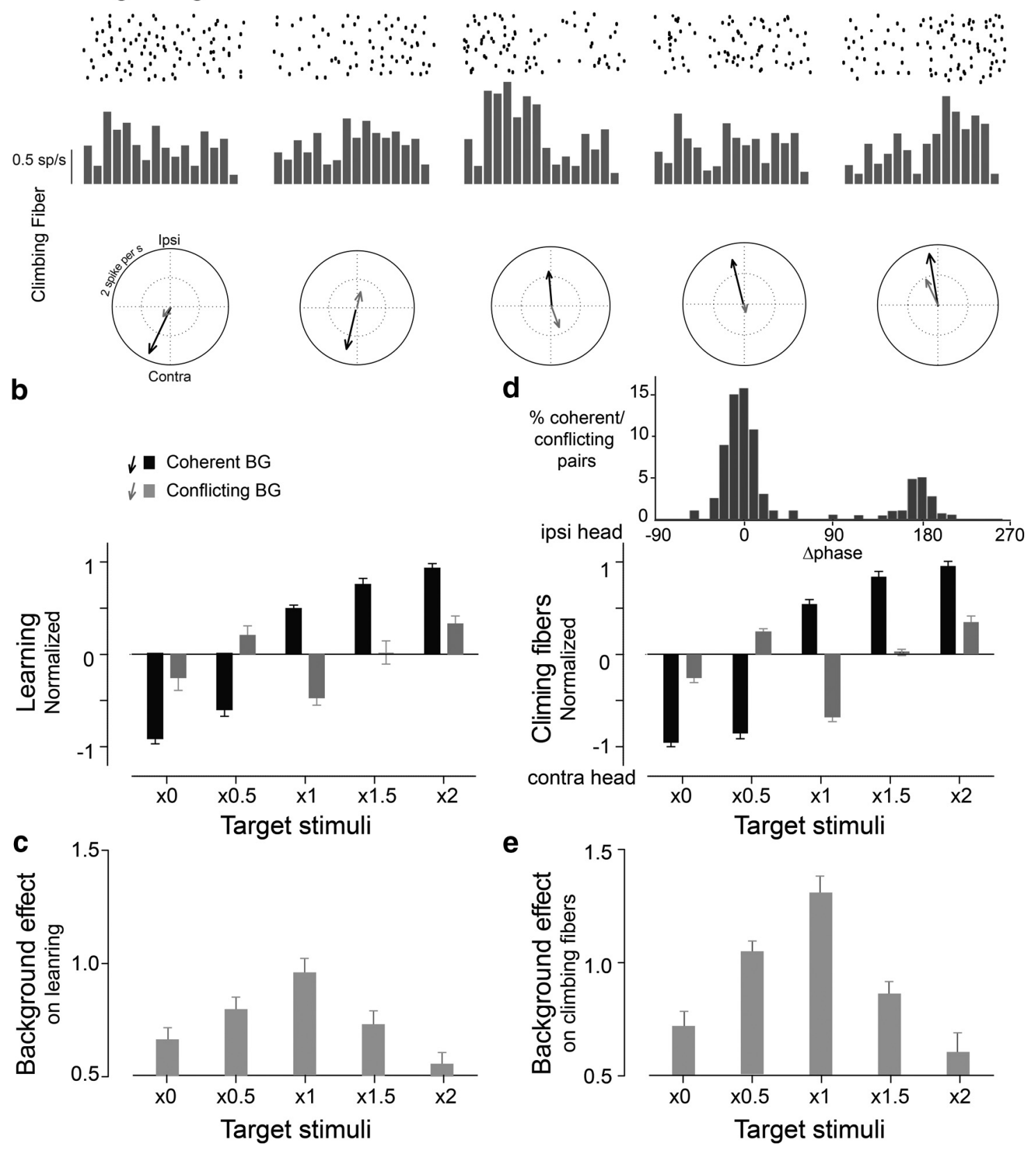

Figure 4. Learning and climbing fiber responses during the coherent (black) and conflicting (gray) training stimuli. $\boldsymbol{a}$, Raster plots, spike frequency histograms, and polar plots showing the responses of a representative climbing fiber to the five pairs of coherent and conflicting training stimuli. $\boldsymbol{b}$, Learned changes in V0R gain induced by training (Figure legend continues.) 

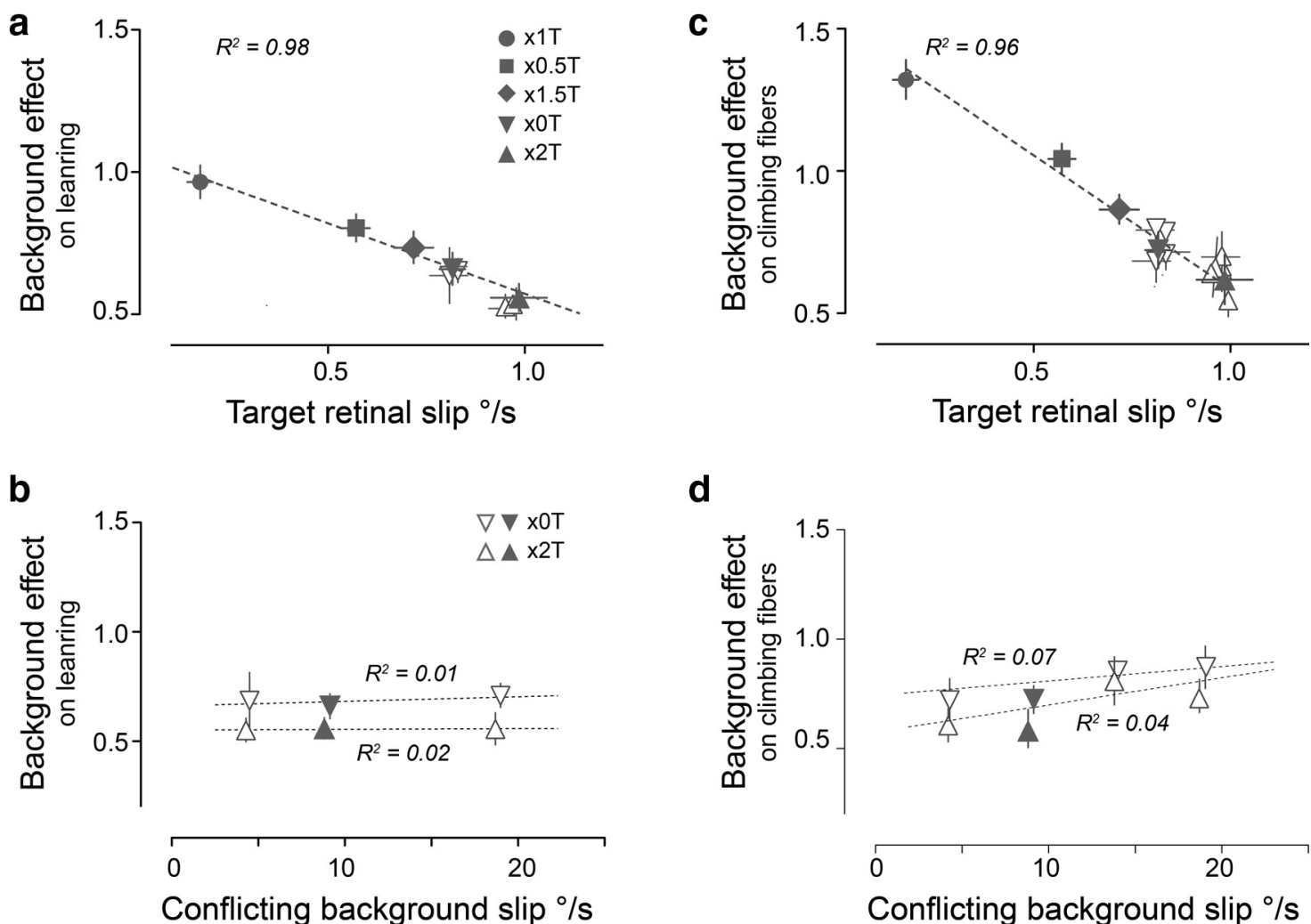

Conflicting background slip $\%$

\section{Conflicting background slip $\%$}

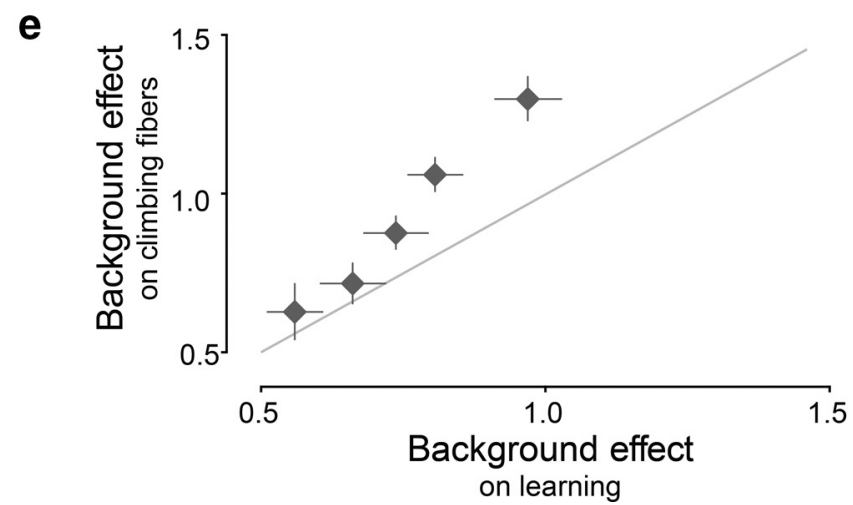

Figure 5. $\boldsymbol{a}-\boldsymbol{d}$, Correlation between the magnitude of the conflicting BG's effects and retinal slip speed of the $T(\boldsymbol{a}, \boldsymbol{c})$ and BG $(\boldsymbol{b}, \boldsymbol{d})$. The effect of conflicting background motion on learning ( $\boldsymbol{a}$ ) and climbing fiber responses (c) was correlated with the peak speed of T slip on the retina, but did not vary with the peak speed of conflicting BG slip on the retina ( $\boldsymbol{b}, \boldsymbol{d})$. Filled symbols represent data from the five pairs of coherent and conflicting training stimuli shown in Figure 3, with a peak BG speed of $10 \%$ relative to the $\mathrm{T}$. Open symbols represent data from additional conflicting training stimuli with $\times 0$ and $\times 2$ Tstimuli and peak BG speeds of $5-20 \%$ s relative to the T.e, The effects of conflicting BG motion on learning plotted against the effects on climbing fiber responses. BG effects on learning and climbing fiber responses were the same as in Figure 4c and Figure 4e, respectively. Gray line: $x=y$.

between the climbing fiber responses during coherent versus conflicting motion of the BG, for each $\mathrm{T}$ condition. The putative error signals carried by the climbing fibers were significantly different when there was conflicting rather than coherent motion of the BG$$
\leftarrow
$$

(Figure legend continued.) stimuli with different T motion (abscissa) and either coherent (black bars) or conflicting (gray bars) BG motion. c, The magnitude of the BG's effect on learning, calculated as the absolute difference between learning induced with coherent versus conflicting motion of the $B G$, for each T condition. $\boldsymbol{d}$, Climbing fiber responses. Top, Histogram of differences in the phase of climbing fiber responses between pairs of coherent and conflicting training stimuli. Bottom, Average amplitude and direction of the climbing fiber responses to coherent training (black bars) and conflicting training stimuli (gray bars). Positive and negative values indicate peak firing during ipsiversive or contraversive head motion, respectively. $\boldsymbol{e}$, The magnitude of the BG's effect on the climbing fibers, calculated as the absolute difference between the climbing fiber responses when there was coherent versus conflicting motion of the $\mathrm{BG}$, for each $\mathrm{T}$ condition.
}

(Fig. 4a, d; $p<0.0001$, ANOVA; $p<0.0001$, post hoc Tukey's test). As observed for learning, the conflicting BG motion affected the climbing fiber signals to varying degrees across the five pairs of coherent and conflicting training stimuli (Fig. $4 d, e$ ). Conflicting BG motion could either reduce or reverse the phase of the climbing fiber responses, compared with the responses during coherent stimuli. Notably, changes in the phase of peak climbing fiber activity were bimodal — having either no effect, or flipping it by $\sim 180^{\circ}$, further supporting the use of a single, scalar value to summarize the climbing fiber responses (Fig. $4 d$, top).

The amplitude of the BG's effects on the climbing fibers was inversely correlated with the speed of T slip on the retina (Fig. $5 c$; $R^{2}=0.96, p<0.001$ ), as was also observed for its effects on learning. However, for a given $\mathrm{T}$ slip, the BG had a greater effect on the climbing fiber responses (Fig. 5c) than on learning (Fig. 
a

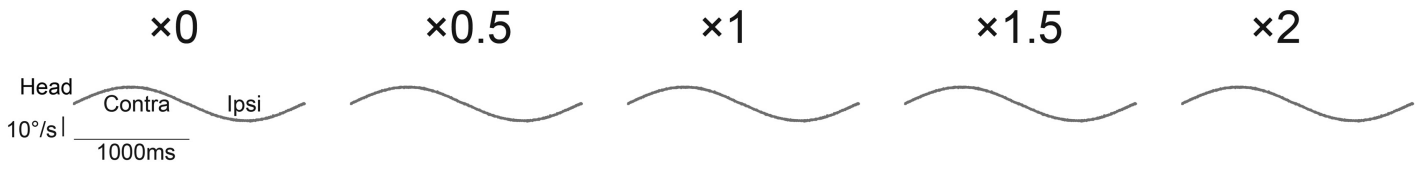

\section{Coherent background}
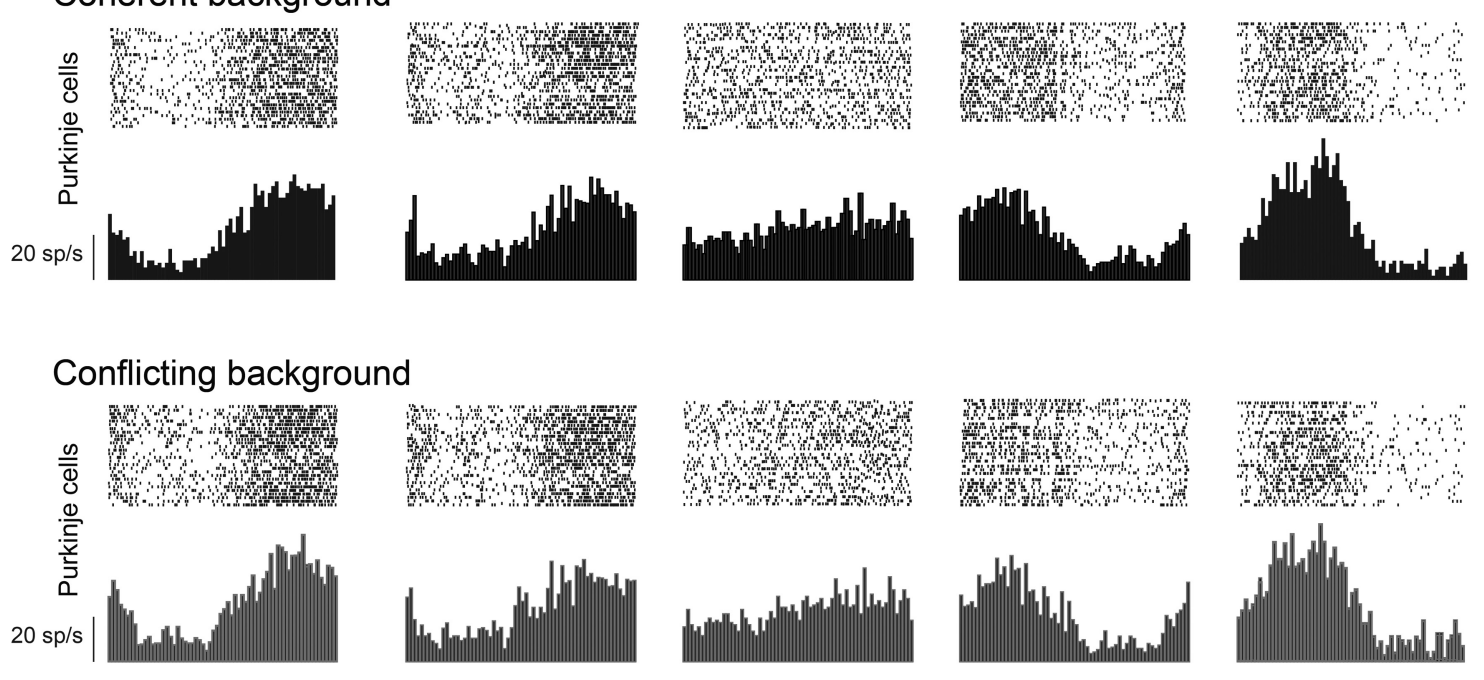

b

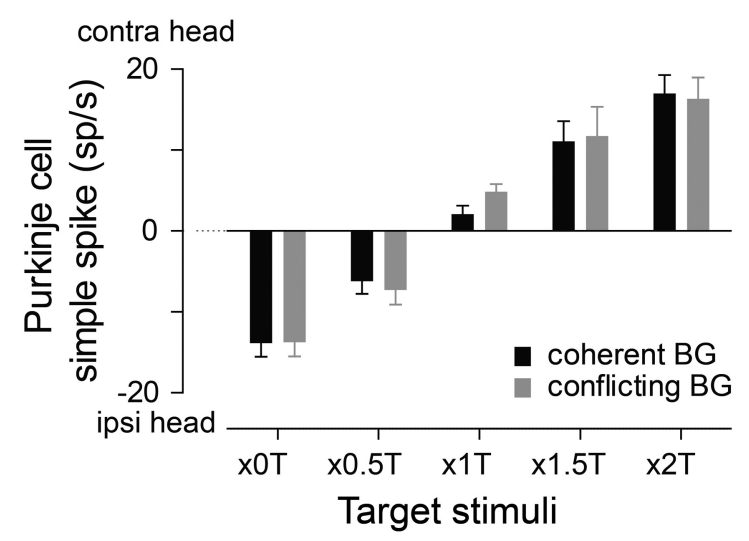

Figure 6. Purkinje cell simple spike responses during training stimuli. $\boldsymbol{a}$, Raster plots and spike frequency histograms of neural responses of a representative Purkinje cell to the five pairs of coherent and conflicting training stimuli. $\boldsymbol{b}$, Purkinje cell simple spike responses to coherent training (black bars) and conflicting training stimuli (gray bars). Positive values indicate peak firing during contraversive head motion, negative values indicate peak firing during ipsiversive head motion. Bars represent the averages from 62 HGVPs recorded in two monkeys. Error bars signify SEM.

$5 a, e)$, indicating that the climbing fiber responses were more sensitive to BG motion. Although sensitive to the direction of BG motion, climbing fiber responses were relatively insensitive to the speed of BG slip for peak speeds between 5 and $20 \%$ s (Fig. $5 d ; R^{2}$ $<0.1, p>0.3)$.

\section{T and BG motion: effects on Purkinje cell simple}

\section{spike responses}

In addition to the climbing fiber responses, we measured the effects of BG motion on the Purkinje cell simple spike responses, which is another candidate neural instructive signal for cerebellum-dependent learning (Miles and Lisberger, 1981; Ke et al., 2009; Nguyen-Vu et al., 2013). As previously reported, Purkinje cell simple spike rate increased during ipsiversive head motion during training stimuli that induced a learned decrease in VOR gain $(\times 0, \times 0.5$; Fig. $6 a, b$, black bars, negative values $)$. In contrast, Purkinje cell simple spike rate increased during contraversive head motion during training stimuli that induced a learned increase in VOR gain $(\times 1, \times 1.5, \times 2$; Fig. $6 a, b$, black bars, positive values). The amplitude of the Purkinje cell simple spike responses was correlated with the T slip speed and the associated eye movements (compare Fig. $6 b$ vs Fig. $2 b, c ; p<$ 0.001 , Pearson correlation analysis). Conflicting BG motion had no significant effect on the simple spike responses of the Purkinje cells (Fig. $6 b$; coherent vs conflicting, ANOVA, $p>$ $0.73)$. Thus, candidate instructive signals in the Purkinje cell simple spikes were influenced only by the motion of the $\mathrm{T}$ during training, and not by the motion of the BG visual stimulus. This contrasts with the candidate instructive signals in the climbing fibers, which were influenced by the motion of both the $\mathrm{T}$ and the $\mathrm{BG}$.

\section{Discussion}

The VOR has been used extensively to study the mechanisms of cerebellum-dependent motor learning (du Lac et al., 1995; Raymond et al., 1996; Boyden et al., 2004; Schubert and Zee, 2010; 
Broussard et al., 2011). In the laboratory, coherent visual motion is usually used to study VOR learning. But in the natural world, image motion would be coherent on the retina only under rare circumstances, if ever. Hence the neural circuitry controlling VOR learning must extract an error signal from a visual scene composed of multiple visual objects. In our experiments with two visual objects, motor learning favored stabilization of a small $\mathrm{T}$ when there were large errors in T stabilization, but learning favored stabilization of the visual BG when errors in T stabilization were small. Here, we consider several factors that could determine the relative influence of the $\mathrm{T}$ and $\mathrm{BG}$.

Previous studies have suggested that the behavioral relevance of a stimulus could gate its ability to influence climbing fiber responses. In animals making visually driven eye movements with the head stationary, motion of an irrelevant BG stimulus was reported to have little or no effect on climbing fiber responses in the floccular complex (Stone and Lisberger, 1990; Frens et al., 2001). Therefore, it was hypothesized that the decision to track a visual stimulus could gate the responses of the climbing fibers so that they would preferentially encode the motion of the visual object controlling the eye movements, with irrelevant information filtered out. Such a representation of the behaviorally relevant errors in eye-movement performance would seem to be an appropriate signal to guide learning. However, under all conditions we tested, the task-irrelevant BG motion had a substantial effect on the climbing fiber responses.

For all of the training stimuli, the $\mathrm{T}$ was more behaviorally relevant, in that it controlled the motor response (eye movements) and the delivery of rewards. In contrast, the BG had no significant effect on the ongoing eye-movement behavior (Fig. $2 b)$. Despite the animals' decision to track the T, BG motion could reduce (Fig. 4a,b,d, $\times 0 \mathrm{~T}, \times 2 \mathrm{~T}$ ), eliminate (Fig. 4a,b,d, $\times 1.5 \mathrm{~T}$ ), or even dominate (Fig. $4 a, b, d, \times 0.5 \mathrm{~T}, \times 1 \mathrm{~T}$ ) the effects of the more behaviorally relevant $\mathrm{T}$ in driving climbing fiber responses and learning. Thus, the sensory cue with the highest task relevance does not necessarily control motor learning, nor do the climbing fibers simply encode the eye-movement performance error, as defined by the visual stimulus controlling the eye movements. Behavioral relevance may have some influence on the relative contribution of the $T$ versus the $B G$, but it does not act as a binary gate. Rather, across a range of $\mathrm{T}$ and $\mathrm{BG}$ combinations, we found graded effects of the BG motion (Fig. $5 a, c$ ), which could not be explained by behavioral relevance.

Retinal slip speed is another factor that can influence climbing fiber responses. In such species as rabbit, cat, and rat, climbing fibers in the flocculus are tuned for low retinal slip speeds, and their responses fall off with speeds $>1-2 \%$ (Simpson and Alley, 1974; Blanks and Precht, 1983; Kusunoki et al., 1990; Fushiki et al., 1994). Tuning for low speeds may explain the reduced sensitivity of climbing fibers to visual objects not controlling eye movements in nonprimate species (Frens et al., 2001), because those objects will tend to have higher retinal slip speeds, which are less effective for driving the climbing fibers. In monkeys, however, most climbing fibers exhibit a maximal response for retinal slip speeds of several degrees per second to $>10^{\circ} / \mathrm{s}$ (Noda et al., 1987; Hoffmann and Distler, 1989). This sensitivity to high speeds may enable BG images to influence climbing fibers, and hence learning, in primates.

In our experiments, the effects of T and BG were not simply additive. Rather, $\mathrm{T}$ motion seems to suppress climbing fiber responses to BG motion in a manner that depends on the speed of T slip on the retina. Graded suppression of the BG's effects by the $\mathrm{T}$ could be directly related to $\mathrm{T}$ speed, or it could be mediated by other factors correlated with T speed, such as eye movements and attention. Previous studies have suggested that the visual signals carried by the climbing fibers might be gated by the presence of a tracking $\mathrm{T}$ at the fovea, the decision to track the $\mathrm{T}$, or by the eye movement that results from that decision (Stone and Lisberger, 1990; Frens et al., 2001). Of these possibilities, our results are most consistent with the eye movements regulating the influence of the visual BG because the graded effects we observed are unlikely to result from a binary signal, such as the presence of a $\mathrm{T}$ or the decision to track it. Eye velocity was linearly correlated with $\mathrm{T}$ speed (Fig. 2b) and with Purkinje cell simple spike output (Fig. $6 b, p<$ $0.0001)$. Purkinje cell output can influence the activity of climbing fibers (Bengtsson and Hesslow, 2006; Chaumont et al., 2013), and thus may account for the ability of T motion to gate the response of the climbing fibers to BG motion. Alternatively, attention could influence the relative effects of potential error cues provided by the two visual stimuli. If greater attention to the $\mathrm{T}$ is required to effectively track it at higher speeds, this could favor the neural representation of the T over the BG "distractor." Currently, little is known about the effect of attention on climbing fiber responses.

Location on the retina could also influence visual responses in the climbing fibers. Visual receptive fields of climbing fibers in the flocculus are large $\left(>10^{\circ}\right.$; Simpson and Alley, 1974; Noda et al., 1987; Graf et al., 1988; Fushiki et al., 1994). Nevertheless, we found that the motion of a small $\mathrm{T}$ could, in some cases, dominate the effects of a large BG visual stimulus on climbing fiber responses. This may reflect privileged access of foveal image motion to the climbing fibers. Visual receptive fields of floccular climbing fibers always include the fovea or central retinal area, and in primates, a small foveal $\mathrm{T}$ is sufficient to elicit robust climbing fiber signals and to support VOR learning (Lisberger and Fuchs, 1978; Stone and Lisberger, 1990; Scudder and Fuchs, 1992; Lisberger, 1994; Shelhamer et al., 1994). However, it seems unlikely that the foveal location of the $\mathrm{T}$ can fully account for its powerful effect on climbing fiber responses, since the BG also occupied part of the fovea during training. The fovea represents the central $2^{\circ}$ of visual space in rhesus monkeys, but the T used in the present experiment only subtended $0.5^{\circ}$ (Rolls and Cowey, 1970).

Thus, the putative neural error signals carried by climbing fibers and motor learning do not identify a single error, but can be simultaneously influenced by more than one error cue, which can be differently weighted by such factors as their physical properties (e.g., speed or location on the retina), cognitive factors (such as attention), or the ongoing eye movements. There are several parallels between these new findings for oculomotor learning and previous findings regarding oculomotor performance in the presence of multiple T's. In particular, smooth pursuit eye movement performance, like VOR learning, can be simultaneously influenced by more than one visual cue, with the relative weighting of cues affected by several factors, including attention, the rewards associated with the different T's, their luminance, and their location on the retina (Ferrera and Lisberger, 1995, 1997; Niu and Lisberger, 2011; Gardner and Lisberger, 2001; Joshua and Lisberger, 2012).

The effects of the T and BG on the climbing fiber responses during training largely paralleled their effects on learning, which is consistent with the idea that the climbing fibers provide instructive signals that guide learning. However, previous work has suggested that learning is not completely determined by climbing fiber signals, but may also be influenced by additional neural instructive signals, such as the simple spike output of Purkinje cells (Miles and Lisberger, 1981; Ke et al., 2009; Nguyen-Vu et al., 2013). Accordingly, we found that the BG's effect on learning was smaller than its effect on the climbing fibers (Fig. $5 e$ ), as one would 
expect if the Purkinje cells, which are not affected by the BG, also contribute to learning. Because these neurons respond to different cues during training, joint control of learning by the climbing fibers and Purkinje cells could expand the capacity of the cerebellar circuit to flexibly draw on different cues to guide learning.

\section{References}

Albus J (1971) A theory of cerebellar function. Math Biosci 10:25-61. CrossRef Bengtsson F, Hesslow G (2006) Cerebellar control of the inferior olive. Cerebellum 5:7-14. CrossRef Medline

Blanks RH, Precht W (1983) Responses of units in the rat cerebellar flocculus during optokinetic and vestibular stimulation. Exp Brain Res 53:1-15. Medline

Boyden ES, Katoh A, Raymond JL (2004) Cerebellum-dependent learning: the role of multiple plasticity mechanisms. Annu Rev Neurosci 27:581609. CrossRef Medline

Broussard DM, Titley HK, Antflick J, Hampson DR (2011) Motor learning in the VOR: the cerebellar component. Exp Brain Res 210:451-463. CrossRef Medline

Chaumont J, Guyon N, Valera AM, Dugué GP, Popa D, Marcaggi P, Gautheron V, Reibel-Foisset S, Dieudonné S, Stephan A, Barrot M, Cassel JC, Dupont JL, Doussau F, Poulain B, Selimi F, Léna C, Isope P (2013) Clusters of cerebellar Purkinje cells control their afferent climbing fiber discharge. Proc Natl Acad Sci U S A 110:16223-16228. CrossRef Medline

du Lac S, Raymond JL, Sejnowski TJ, Lisberger SG (1995) Learning and memory in the vestibulo-ocular reflex. Annu Rev Neurosci 18:409-441. CrossRef Medline

Eccles SJC, Ito M, Szentagothai J (1967) The cerebellum as a neuronal machine. New York: Springer.

Ferrera V, Lisberger S (1997) The effect of a moving distractor on the initiation of smooth-pursuit eye movements. Vis Neurosci 14:323-338. Medline

Ferrera VP, Lisberger SG (1995) Attention and target selection for smooth pursuit eye movements. J Neurosci 15:7472-7484. Medline

Frens MA, Mathoera AL, van der Steen J (2001) Floccular complex spike response to transparent retinal slip. Neuron 30:795-801. CrossRef Medline

Fushiki H, Sato Y, Miura A, Kawasaki T (1994) Climbing fiber responses of Purkinje cells to retinal image movement in cat cerebellar flocculus. J Neurophysiol 71:1336-1350. Medline

Gardner JL, Lisberger SG (2001) Linked target selection for saccadic and smooth pursuit eye movements. J Neurosci 21:2075-2084. Medline

Ghelarducci B, Ito M, Yagi N (1975) Impulse discharges from flocculus Purkinje cells of alert rabbits during visual stimulation combined with horizontal head rotation. Brain Res 87:66-72. CrossRef Medline

Gonshor A, Jones GM (1976) Short-term adaptive changes in the human vestibulo-ocular reflex arc. J Physiol 256:361-379. Medline

Graf W, Simpson JI, Leonard CS (1988) Spatial organization of visual messages of the rabbit's cerebellar flocculus. II. Complex and simple spike responses of Purkinje cells. J Neurophysiol 60:2091-2121. Medline

Guo CC, Raymond JL (2010) Motor learning reduces eye movement variability through reweighting of sensory inputs. J Neurosci 30:1624116248. CrossRef Medline

Hoffmann KP, Distler C (1989) Quantitative analysis of visual receptive fields of neurons in nucleus of the optic tract and dorsal terminal nucleus of the accessory optic tract in macaque monkey. J Neurophysiol 62:416-428. Medline

Ito M, Kano M (1982) Long-lasting depression of parallel fiber-Purkinje cell transmission induced by conjunctive stimulation of parallel fibers and climbing fibers in the cerebellar cortex. Neurosci Lett 33:253-258. CrossRef Medline

Ito M, Shiida T, Yagi N, Yamamoto M (1974) Visual influence on rabbit horizontal vestibulo-ocular reflex presumably effected via the cerebellar flocculus. Brain Res 65:170-174. CrossRef Medline

Ito M, Nisimaru N, Yamamoto M (1977) Specific patterns of neuronal connexions involved in the control of the rabbit's vestibulo-ocular reflexes by the cerebellar flocculus. J Physiol 265:833-854. Medline

Joshua M, Lisberger SG (2012) Reward action in the initiation of smooth pursuit eye movements. J Neurosci 32:2856-2867. CrossRef Medline

Ke MC, Guo CC, Raymond JL (2009) Elimination of climbing fiber instructive signals during motor learning. Nat Neurosci 12:1171-1179. CrossRef Medline

Kimpo RR, Rinaldi JM, Kim CK, Payne HL, Raymond JL (2014) Gating of neural error signals during motor learning. Elife 3:e02076. CrossRef Medline

Kusunoki M, Kano M, Kano MS, Maekawa K (1990) Nature of optokinetic response and zonal organization of climbing fiber afferents in the vestibulocerebellum of the pigmented rabbit. Exp Brain Res 80:225-237. Medline

Lee TD, Schmidt RA (2005) Motor control and learning, 4th edition. Champaign, IL: Human Kinetics.

Lisberger SG (1994) Neural basis for motor learning in the vestibuloocular reflex of primates. III. Computational and behavioral analysis of the sites of learning. J Neurophysiol 72:974-998. Medline

Lisberger SG, Fuchs AF (1978) Role of primate flocculus during rapid behavioral modification of vestibuloocular reflex. I. Purkinje cell activity during visually guided horizontal smooth-pursuit eye movements and passive head rotation. J Neurophysiol 41:733-763. Medline

Lisberger SG, Pavelko TA, Bronte-Stewart HM, Stone LS (1994) Neural basis for motor learning in the vestibuloocular reflex of primates. II. Changes in the responses of horizontal gaze velocity Purkinje cells in the cerebellar flocculus and ventral paraflocculus. J Neurophysiol 72:954-973. Medline

Marr D (1969) A theory of cerebellar cortex. J Physiol 202:437-470. Medline

Medina JF, Lisberger SG (2008) Links from complex spikes to local plasticity and motor learning in the cerebellum of awake-behaving monkeys. Nat Neurosci 11:1185-1192. CrossRef Medline

Miles FA, Fuller JH (1974) Adaptive plasticity in the vestibulo-ocular responses of the rhesus monkey. Brain Res 80:512-516. CrossRef Medline

Miles FA, Lisberger SG (1981) Plasticity in the vestibulo-ocular reflex: a new hypothesis. Annu Rev Neurosci 4:273-299. CrossRef Medline

Miles FA, Fuller JH, Braitman DJ, Dow BM (1980) Long-term adaptive changes in primate vestibuloocular reflex. III. Electrophysiological observations in flocculus of normal monkeys. J Neurophysiol 43:1437-1476. Medline

Nagao S (1988) Behavior of floccular Purkinje cells correlated with adaptation of horizontal optokinetic eye movement response in pigmented rabbits. Exp Brain Res 73:489-497. CrossRef Medline

Nguyen-Vu TD, Kimpo RR, Rinaldi JM, Kohli A, Zeng H, Deisseroth K, Raymond JL (2013) Cerebellar Purkinje cell activity drives motor learning. Nat Neurosci 16:1734-1736. CrossRef Medline

Niu Y-Q, Lisberger SG (2011) Sensory versus motor loci for integration of multiple motion signals in smooth pursuit eye movements and human motion perception. J Neurophysiol 106:741-753. CrossRef Medline

Noda H, Warabi T, Ohno M (1987) Response properties and visual receptive fields of climbing and mossy fibers terminating in the flocculus of the monkey. Exp Neurol 95:455-471. CrossRef Medline

Raymond JL, Lisberger SG (1998) Neural learning rules for the vestibuloocular reflex. J Neurosci 18:9112-9129. Medline

Raymond JL, Lisberger SG, Mauk MD (1996) The cerebellum: a neuronal learning machine? Science 272:1126-1131. CrossRef Medline

Robinson DA (1963) A method of measuring eye movement using a scleral search coil in a magnetic field. IEEE Trans Biomed Eng 10:137-145. Medline

Robinson DA (1976) Adaptive gain control of vestibuloocular reflex by the cerebellum. J Neurophysiol 39:954-969. Medline

Rolls ET, Cowey A (1970) Topography of the retina and striate cortex and its relationship to visual acuity in rhesus monkeys and squirrel monkeys. Exp Brain Res 10:298-310. Medline

Schubert MC, Zee DS (2010) Saccade and vestibular ocular motor adaptation. Restor Neurol Neurosci 28:9-18. Medline

Scudder CA, Fuchs AF (1992) Physiological and behavioral identification of vestibular nucleus neurons mediating the horizontal vestibuloocular reflex in trained rhesus monkeys. J Neurophysiol 68:244-264. Medline

Shadmehr R, Smith MA, Krakauer JW (2010) Error correction, sensory prediction, and adaptation in motor control. Annu Rev Neurosci 33:89-108. CrossRef Medline

Shelhamer M, Tiliket C, Roberts D, Kramer PD, Zee DS (1994) Short-term vestibulo-ocular reflex adaptation in humans. Exp Brain Res 100:328336. Medline

Simpson JI, Alley KE (1974) Visual climbing fiber input to rabbit vestibulocerebellum: a source of direction-specific information. Brain Res 82:302308. CrossRef Medline

Stone LS, Lisberger SG (1990) Visual responses of Purkinje cells in the cerebellar flocculus during smooth-pursuit eye movements in monkeys. II. Complex spikes. J Neurophysiol 63:1262-1275. Medline

Waespe W, Henn V (1981) Visual-vestibular interaction in the flocculus of the alert monkey II. Purkinje cell activity. Exp Brain Res 43:349-360. Medline

Watanabe E (1984) Neuronal events correlated with long-term adaptation of the horizontal vestibulo-ocular reflex in the primate flocculus. Brain Res 297:169-174. CrossRef Medline 